\title{
Época e Densidade de Semeadura de Aveia Preta (Avena strigosa Schreb.) e Azevém (Lolium multiflorum Lam.) no Alto Vale do Itajaí, Santa Catarina
}

\author{
Jefferson Araújo Flaresso ${ }^{1}$, Celomar Daison Gross ${ }^{2}$, Edison Xavier de Almeida1
}

\begin{abstract}
RESUMO - O experimento foi conduzido na Epagri, Estação Experimental de Ituporanga, SC, com o objetivo de determinar a época e a densidade de semeadura de Avena strigosa Schreb. (aveia preta) e Lolium multiflorum Lam. (azevém). Os tratamentos foram avaliados por três anos, dispostos num delineamento de blocos casualizados, em parcelas subdivididas com três repetições. As épocas de semeadura para as duas espécies foram: Época 1 - meados de março; Época 2 - meados de abril; Época 3 - meados de maio; Época 4 - meados de junho. As densidades de sementes puras viáveis foram: aveia preta, 60,80 e $100 \mathrm{~kg} / \mathrm{ha}$; azevém, 15, $25 \mathrm{e} 35 \mathrm{~kg} / \mathrm{ha}$. A aveia preta foi menos produtiva e mais precoce que o azevém. Para as duas espécies, não houve diferença significativa entre as densidades de semeaduras. A melhor época de implantação das espécies foi em meados de abril.
\end{abstract}

Palavras-chave: Avena strigosa Schreb., Lolium multiflorum Lam., rendimento de matéria seca, semeadura

\section{Seeding Date and Density for Avena strigosa Schreb. and Lolium multiflorum Lam. for the Alto Vale do Itajaí Region, Santa Catarina State, Brazil.}

\begin{abstract}
The experiment was conducted for three years at the Epagri, Ituporanga Experimental Station, located on Southern Brazil $\left(27^{\circ} 38^{\prime} \mathrm{S}, 43^{\circ} 60^{\prime} \mathrm{W}\right)$, to evaluate the best seeding date and density for Avena strigosa Schreb. and Lolium multiflorum Lam. at the Alto Vale do Itajaí Region. The experimental design was based on randomized blocks, with subdivided plots and three replicates. Time treatments were: $\mathrm{T} 1=$ middle of March; T2 = middle of April; T3 = middle of May; T4 = middle of June. Densities for A. strigos $a$ were 60,80 and $100 \mathrm{~kg} / \mathrm{ha}$ and for Lolium multiflorum, 15, 25 and $35 \mathrm{~kg} / \mathrm{ha}$. Results showed A. strigosa less productive but more precocious that Lolium multiflorum, but no significant differences were observed on seeding density. The best time for seeding both species was April.
\end{abstract}

Key Words: Avena strigosa Schreb., Lolium multiflorum Lam., dry matter yield, seeding date

\section{Introdução}

A região do Alto Vale do Itajaí, Santa Catarina, caracteriza-se pela predominância de pequenas propriedades, com atividade agropecuária diversificada. O relevo é acidentado e a fertilidade natural dos solos é baixa. Nesse contexto, a produção leiteira apresenta destaque, sendo a região responsável por aproximadamente $17,2 \%$ em relação ao volume total do leite produzido no Estado de Santa Catarina (INSTITUTO CEPA, 1999).

O sistema de alimentação adotado baseia-se no rendimento forrageiro da pastagem nativa, que concentra a produção na primavera e no verão, o que obriga a utilização de outras áreas da propriedade para a produção de forragem que é fornecida no cocho. Em função desta característica, a carência alimentar, principalmente no outono e inverno, é um dos pontos críticos para a pecuária regional, refletin- do em baixa produção média de leite, que é de aproximadamente 1732 litros/vaca/ano (INSTITUTO CEPA, 1999). Dessa forma, as pastagens de gramíneas anuais de inverno consistem em uma alternativa utilizada na região, para fornecimento de alimento de boa qualidade no período crítico (TCACENCO e HILLESHEIM, 1990).

ALMEIDA et al. (2000) recomendam o plantio de aveia preta e azevém, no período de abril a maio, na região subtropical úmida (Cfa) do Estado, sugerindo densidades de $80 \mathrm{~kg} / \mathrm{ha}$ para aveia preta e 25 a 30 $\mathrm{kg} / \mathrm{ha}$ para azevém. Para as condições de clima temperado úmido Cfb, VIDOR et al. (1997) indicam a semeadura de gramíneas anuais de inverno, a partir da segunda quinzena de fevereiro, até o final de maio, utilizando 70 a $90 \mathrm{~kg} /$ ha de sementes para aveia preta e 25 a $30 \mathrm{~kg} / \mathrm{ha}$ para azevém. Nas mesmas condições anteriores, ROSA et al. (2000) recomendam o plantio de aveia preta e azevém de fevereiro a abril, utilizando 
100 e $25 \mathrm{~kg} / \mathrm{ha}$ de sementes, respectivamente. Os autores apenas mencionam a época e densidade utilizadas com essas espécies, desconhecendo-se experimentos específicos, com objetivo de determinar as épocas e densidades adequadas de plantio dessas espécies, nas condições do Alto Vale do Itajaí. Assim, este trabalho foi conduzido buscando atingir este objetivo.

\section{Material e Métodos}

O experimento foi conduzido na Epagri - Estação Experimental de Ituporanga - SC, localizada na região do Alto Vale do Itajaí, com altitude de $475 \mathrm{~m}$ e clima subtropical úmido (Cfa), segundo a classificação de Köeppen, tendo uma duração de três anos (1996 a 1998). O solo utilizado correspondeu a um Cambissolo Distrófico Álico, com topografia suavemente ondulada, submetido ao preparo convencional, calagem e adubação, conforme recomendações de Bartz et al. (1995), para gramíneas da estação fria. Não houve necessidade de calagem, sendo a adubação de base aplicada em 1996 e constituída de $20 \mathrm{~kg} / \mathrm{ha}$ de nitrogênio (N), $70 \mathrm{~kg} / \mathrm{ha}$ de $\mathrm{P}_{2} \mathrm{O}_{5}$ e $60 \mathrm{~kg} / \mathrm{ha}$ de $\mathrm{K}_{2} \mathrm{O}$. O N foi aplicado em cobertura, em duas doses de $35 \mathrm{~kg} / \mathrm{ha}$ em cada tratamento após o primeiro e segundo cortes, respectivamente. No ano de 1997, a área não necessitou de calcário, fósforo $(\mathrm{P})$ e potássio (K), sendo aplicado $50 \mathrm{~kg} / \mathrm{ha}$ de N, após cada corte. Em 1998, também não houve necessidade de calcário, $\mathrm{P}$ e K, sendo aplicados $20 \mathrm{~kg} / \mathrm{ha}$ de $\mathrm{N}$ no plantio e $40 \mathrm{~kg} / \mathrm{ha}$ após o primeiro e segundo cortes, respectivamente.

O experimento foi conduzido em delineamento de blocos casualizados, em parcelas subdivididas, com três repetições, sendo que as espécies Avena strigosa Schreb. (aveia preta) e Lolium multiflorum Lam. (azevém), constituíram as parcelas principais, enquanto as épocas de semeadura, constituíram as subparcelas e as densidades de semeadura as subsubparcelas. As épocas de semeadura foram: Ano de 1996: 12/03, 11/04, 13/05 e 13/06. Ano 1997: 11/03, 11/04, 12/05 e 11/06. Ano 1998: 12/03, 13/04, $12 / 05$ e 12/06. As densidades de semeadura de aveia preta foram: $60 \mathrm{~kg} / \mathrm{ha}$ de sementes puras viáveis, $80 \mathrm{~kg} / \mathrm{ha} \mathrm{e} 100 \mathrm{~kg} / \mathrm{ha}$. Para azevém foram: $15 \mathrm{~kg} / \mathrm{ha}$ de sementes puras viáveis, $25 \mathrm{~kg} / \mathrm{ha}$ e $35 \mathrm{~kg} / \mathrm{ha}$. As unidades experimentais eram constituídas de parcelas de $2 \mathrm{~m}$ x $4 \mathrm{~m}$, sendo a área útil de $0,9 \mathrm{~m} \times 3,0 \mathrm{~m}$. Os cortes da forragem eram efetuados com motosegadeira de parcelas, sendo o primeiro realizado quando as plantas de aveia preta atingiam $30 \mathrm{~cm}$ e o azevém $25 \mathrm{~cm}$. A freqüência dos cortes foi de quatro semanas ( 28 dias), e a $7 \mathrm{~cm}$ de altura do solo. As amostras colhidas a cada corte foram pesadas e secas em estufa a $60-65^{\circ} \mathrm{C}$, por aproximadamente 72 horas para a obtenção da percentagem e rendimento de matéria seca.

A análise estatística dos dados foi realizada por intermédio do programa SAS, versão 6.0 (SAS INSTITUTE INCORPORATION, 1990).

\section{Resultados e Discussão}

Observa-se o ciclo precoce da aveia preta na Tabela 1, com a primeira utilização da pastagem levando 52 e 51 dias, respectivamente, para épocas de semeadura de março e abril. Destaca-se também o maior número de cortes para estas épocas, proporcionando maior período de utilização da pastagem. Com relação às épocas de maio e junho, observa-se um período mais longo, até a primeira utilização, período curto de duração da pastagem e menor número de cortes (Tabela 1). Este aspecto pode ser atribuído a condições pouco favoráveis de precipitação (principalmente em maio, Tabela 3), além da temperatura, ser mais baixa (Tabela 2), reduzindo a taxa de crescimento, além da antecipação do final do ciclo vegetativo, em plantios tardios. Estas tendências foram observadas nos trabalhos de MOZZER et al. (1980) e TCACENCO e HILLESHEIM (1990).

Tabela 1 - Número de dias da semeadura até a primeira utilização, duração do período de utilização da pastagem, e número total de cortes de aveia preta, em função de épocas de semeadura. Média de três anos

Table 1 - Days number of seeding until first utilization, duration of pasture and number total of cuts for Avena strigosa, according to time seeding. Mean of three years

\begin{tabular}{|c|c|c|c|c|}
\hline $\begin{array}{l}\text { Épocas de semeadura } \\
\text { Seeding date }\end{array}$ & $\begin{array}{l}\text { Março } \\
\text { March }\end{array}$ & $\begin{array}{l}\text { Abril } \\
\text { April }\end{array}$ & $\begin{array}{l}\text { Maio } \\
\text { May }\end{array}$ & $\begin{array}{r}\text { Junho } \\
\text { June }\end{array}$ \\
\hline $\begin{array}{l}\text { Dias até } 1^{\mathrm{a}} \text { utilização } \\
\text { Days until first utilization }\end{array}$ & $52^{\mathrm{a} *}$ & $51^{\mathrm{a}}$ & $68^{\mathrm{b}}$ & $64^{\mathrm{b}}$ \\
\hline $\begin{array}{l}\text { Duração da pastagem (dias) } \\
\text { Duration of pasture (days) }\end{array}$ & $122^{a}$ & $97 b$ & $65^{c}$ & $48^{d}$ \\
\hline $\begin{array}{l}\text { Cortes }\left(\mathrm{N}^{\mathrm{o}}\right) \\
\text { Cuts (number) }\end{array}$ & $5,3^{\mathrm{a}}$ & $4,3^{\mathrm{a}}$ & $3,3^{\mathrm{ab}}$ & $2,7^{\mathrm{b}}$ \\
\hline
\end{tabular}

* Na linha, letras iguais não diferem estatisticamente (Duncan, 5\%).

* Means, within a row, followed by the same letter are not different $(P>$.05) by Duncan test.

Rev. bras. zootec., 30(6S):1969-1974, 2001 


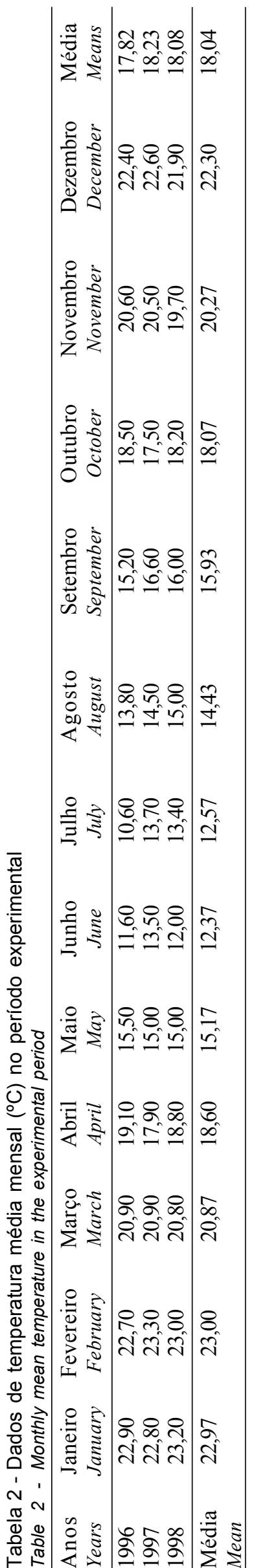

Observa-se na Tabela 4 que o azevém teve melhor comportamento com o plantio realizado em abril, quando houve maior número de cortes e duração da pastagem. Na época de março, os resultados foram semelhantes a abril em relação à duração e ao número de cortes, mas a primeira utilização ocorreu mais tarde em março. Esta diferença pode ser explicada pela baixa precipitação, principalmente em 1997 (Tabela 3), interagindo com temperatura média mais elevada, no mês de março.

Nesta mesma linha de trabalho, Josifovich et al. (1968) relatam um menor número de dias da semeadura até a primeira utilização, quando é efetuada a semeadura mais cedo, para aveia e azevém e salientam a duração do período útil da pastagem, variando de 163 (março) a 82 dias (maio) para aveia preta e de 120 (março) a 75 dias (maio), para azevém.

$\mathrm{O}$ rendimento de matéria seca de aveia preta, observa-se na Tabela 5 que não houve diferença significativa $(\mathrm{P}>0,05)$ entre as densidades de semeadura e interação com a época de semeadura. KALVELAGE et al. (1989), nas condições do Planalto Catarinense, utilizando 51, 71 e $100 \mathrm{~kg} / \mathrm{ha}$ de sementes de aveia preta, também não encontraram diferenças significativas, com produções de 3992, 4007 e 4466 kg/ha de matéria seca, respectivamente, valores esses superiores aos obtidos neste trabalho. ALVIM e MARTINS (1986), em Minas Gerais, encontraram melhores resultados utilizando $30 \mathrm{~kg} /$ ha de sementes para aveia preta, mas recomendaram $50-60 \mathrm{~kg} / \mathrm{ha}$ para garantir boa formação da pastagem. Nas condições de clima Cfa, onde foi conduzido o presente experimento, ALMEIDA et al. (2000) recomendam o plantio de aveia com $80 \mathrm{~kg} /$ ha de sementes. As recomendações citadas ficam próximas às utilizadas neste trabalho. No que diz respeito à época de semeadura de aveia preta, resultados na Tabela 5, observa-se maior rendimento em abril, o qual não diferiu de maio e junho, sendo porém superior a março.

Estes resultados não estão de acordo com TCACENCO e HILLESHEIM (1990), que apontam meados de março como a época ideal para plantio. Em contrapartida, Almeida et al. (2000), para clima $\mathrm{Cfa}$, recomendam o plantio de abril a maio, o que condiz com os resultados obtidos neste ensaio. As recomendações para regiões mais frias de Santa Catarina, se estendem de fevereiro a abril (ROSA et al., 2000).

O rendimento de matéria seca obtido com azevém 


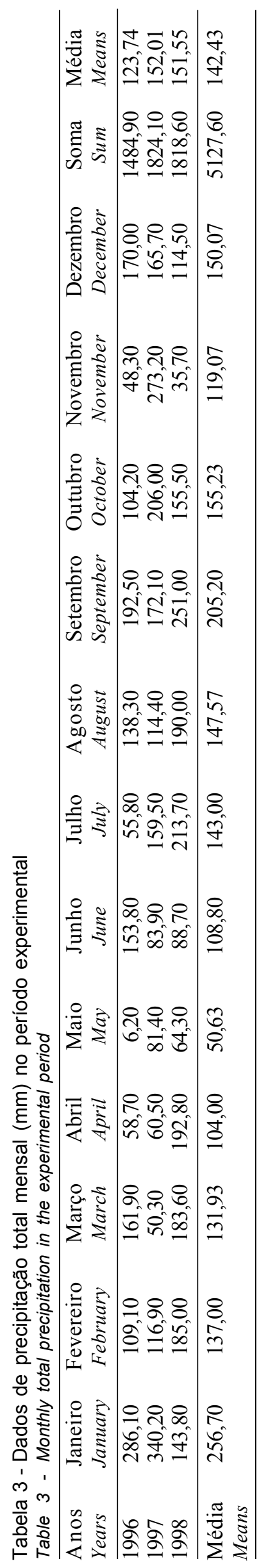

está listado na Tabela 6. Para esta espécie também não houve interação significativa entre densidade $e$ época de semeadura. As densidades de semeadura testadas não foram diferentes estatisticamente $(\mathrm{P}>0,05)$. Esta mesma tendência foi obtida por KALVELAGE et al. (1989), que testaram 13, 18 e $25 \mathrm{~kg} / \mathrm{ha}$ de sementes e obtiveram rendimentos de 7218,7226 e $7436 \mathrm{~kg} /$ ha de matéria seca, respectivamente. Entretanto, ALVIM e MARTINS (1986) encontraram o melhor resultado com a utilização de 19 $\mathrm{kg} / \mathrm{ha}$ de sementes, recomendando de 15 a $20 \mathrm{~kg} / \mathrm{ha}$, para garantir a melhor formação da pastagem. JOSIFOVICH et al. (1968) recomendam a utilização de 25 a $30 \mathrm{~kg} / \mathrm{ha}$ de sementes, o que está dentro da faixa testada no presente experimento. Estas mesmas densidades de semeadura são citadas por ROSA et al. (2000) para regiões mais frias e ALMEIDA et al. (2000), para regiões mais quentes de Santa Catarina. Entre as épocas de semeadura testadas para o azevém, (Tabela 6) observa-se maior rendimento para abril, seguido de março e maio, que não diferiram entre si, sendo que maio também não foi superior a junho.

Estes resultados diferem dos citados por TCACENCO e HILLESHEIM (1990), que recomendam o plantio de azevém em março, nas condições de clima Cfa do Estado. Em contrapartida, ALMEIDA et al. (2000), para as mesmas condições climáticas, apontam abril a maio, como melhor época para plantio do azevém, assim como Salerno e VETTERLE (1984). Para regiões mais frias, ROSA et al. (2000) citam o plantio de azevém a partir de fevereiro.

Tabela 4 - Número de dias da semeadura até a primeira utilização, duração do período de utilização da pastagem e número total de cortes de azevém, em função da época de semeadura. Média de três anos

Table 4 - Days number of seeding until first utilization, duration of pasture and number total of cuts for Lolium multiflorum according to time seeding. Mean of three years

Épocas de semeadura Março Abril Maio Junho Seedingdate March April May June

Dias até $1^{\mathrm{a}}$ utilização

Days until first utilization

$\begin{array}{lllll}\text { Duração da pastagem (dias) } & 122^{\mathrm{a}} & 120^{\mathrm{a}} & 80^{\mathrm{b}} & 63^{\mathrm{c}}\end{array}$

Duration of pasture (days)

Cortes $\left(\mathrm{N}^{\mathrm{o}}\right)$

$5,3^{\mathrm{a}} \quad 5,3^{\mathrm{a}} \quad 3,7^{\mathrm{d}} \quad 3,0^{\mathrm{b}}$

Cuts (number)

* Na linha, letras iguais não diferem estatisticamente (Duncan, $5 \%$ ).

* Means, within a row, followed by the same letter are not different $(P>05)$ by

Duncan test. 
Tabela 5 - Rendimento de matéria seca de aveia preta em função de densidades e épocas de semeadura. Média de três anos Table 5 - Dry matter yield of Avena strigosa according to densities and seeding dates. Mean of three years.

\begin{tabular}{|c|c|c|c|c|c|c|}
\hline \multirow[t]{2}{*}{$\begin{array}{l}\text { Espécie } \\
\text { Specie }\end{array}$} & \multirow[t]{2}{*}{$\begin{array}{c}\text { Densidade } \\
\text { Density }(\mathrm{kg} / \mathrm{ha})\end{array}$} & \multicolumn{5}{|c|}{$\begin{array}{c}\text { Épocas de semeadura } \\
\text { Seeding date }\end{array}$} \\
\hline & & $\begin{array}{l}\text { Março } \\
\text { March }\end{array}$ & $\begin{array}{l}\text { Abril } \\
\text { April }\end{array}$ & $\begin{array}{l}\text { Maio } \\
\text { May }\end{array}$ & $\begin{array}{l}\text { Junho } \\
\text { June }\end{array}$ & $\begin{array}{l}\text { Média* } \\
\text { Mean }\end{array}$ \\
\hline Aveia preta & 60 & 1398 & 2077 & 1814 & 1773 & $1766^{\mathrm{a}}$ \\
\hline \multirow{4}{*}{ Avena strigosa } & 80 & 1411 & 2226 & 2035 & 1892 & $1891^{\mathrm{a}}$ \\
\hline & 100 & 1501 & 2428 & 2107 & 2058 & $2023^{\mathrm{a}}$ \\
\hline & Média** & $1437^{\mathrm{B}}$ & $2243^{\mathrm{A}}$ & $1985^{\mathrm{AB}}$ & $1908^{\mathrm{AB}}$ & 1893 \\
\hline & Mean & & & & & \\
\hline
\end{tabular}

* Na coluna, letras minúsculas iguais não diferem estatisticamente (DUNCAN, 5\%).

** Na linha, letras maiúsculas iguais não diferem estatisticamente (DUNCAN, 5\%).

* In the column, means followed by the same small letter are not different (P>.05) by Duncan test.

** In the line, means followed by the same capital letter are not different $(P>.05)$ by Duncan test.

Tabela 6 - Rendimento de matéria seca de azevém em função de densidades e épocas de semeadura. Média de três anos Table 6 - Dry matter yield of Lolium multiflorum according to densities and seeding datess. Mean of three years

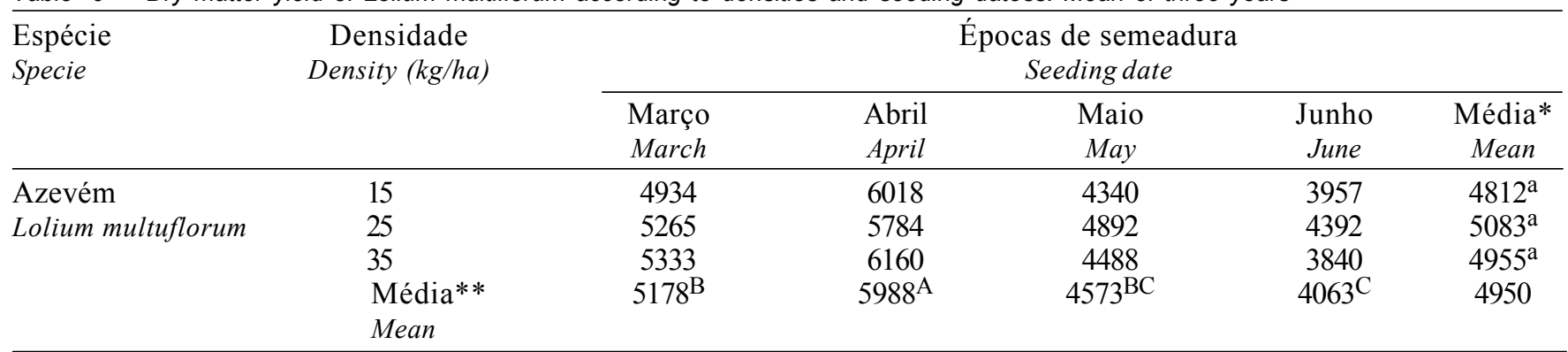

* Na coluna, letras minúsculas iguais não diferem estatisticamente (DUNCAN, 5\%).

** Na linha, letras maiúsculas iguais não diferem estatisticamente (DUNCAN, 5\%).

* Means, within a column, followed by the same small letter are not different $(P>05)$ by Duncan test.

** Means, within a row, followed by the same capital letter are not different $(P>05)$ by Duncan test.

A distribuição estacional do rendimento de matéria seca de aveia preta, de acordo com as épocas de semeadura, está demonstrada na Figura 1.

Observa-se que a semeadura mais cedo proporciona maior disponibilidade de forragem no período de outono e inverno, justamente a época mais crítica para a produção de forragem na região do Alto Vale do Itajaí. Na semeadura de maio e junho, há pequena produção no inverno, sendo a maior porção concentrada na primavera. O azevém comporta-se de forma mais tardia que a aveia preta e, nas épocas de março e abril, teve maior participação do rendimento no inverno e primavera, enquanto para as semeaduras em maio e junho a maior produção ocorreu na primavera (Figura 2).

Os resultados alcançados neste ensaio, estão de acordo com os obtidos por SALERNO e VETTERLE (1984), os quais concluíram que essas forrageiras apresentam baixo potencial como alternativa outonal,

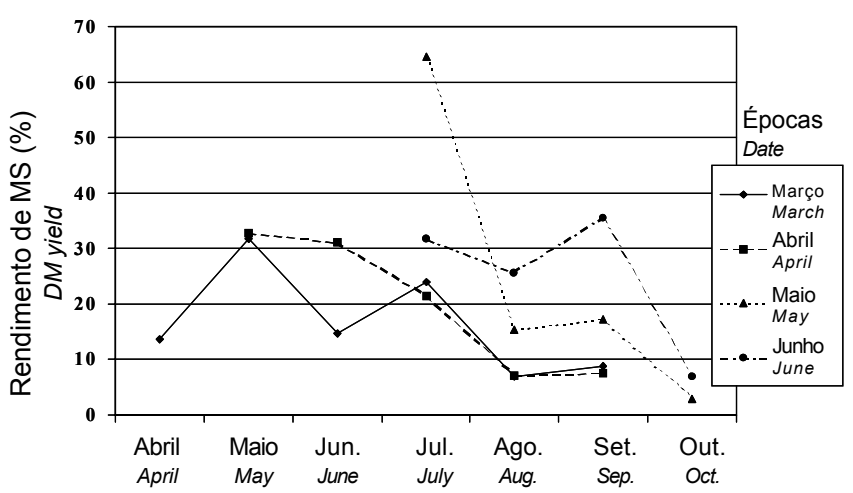

Figura 1 - Distribuição estacional do rendimento de matéria seca de Avena strigosa, em função das épocas de semeadura. Média de 3 anos.

Figure 1 - Seasonal distribution of dry matter yield of Avena strigosa, according to seeding seasons. Mean of three years. 


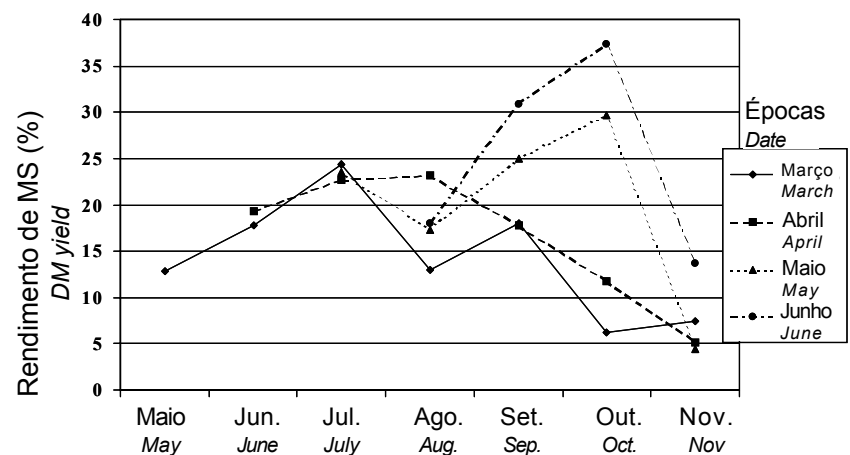

Figura 2 - Distribuição estacional do rendimento de matéria seca de Lolium multiflorum em função das épocas de semeadura. Médias de 3 anos.

Figure 2 - Seasonal distribuition of dry matter yield of Lolium multiflorum according to seeding seasons. Means of three years.

de produção de forragem, concentrando o rendimento no inverno e primavera, e que os meses mais adequados à semeadura foram abril e maio. Neste aspecto, POSTIGLIONI (1982), em região de clima $\mathrm{Cfb}$ do Paraná, detectou que o azevém, foi mais tardio que aveia, concentrando $70 \%$ de sua produção em agosto e setembro, enquanto a aveia concentrou $60 \%$ em junho e julho.

\section{Conclusões}

O mês de abril consiste na melhor época de semeadura de aveia preta e azevém anual no Alto Vale do Itajaí, Santa Catarina.

Semeada em abril, a aveia preta produziu em torno de $15 \%$ a mais de matéria seca, seu período vegetativo foi 40 dias mais longo, em comparação com as semeaduras feitas em maio e junho. Isso propiciou um corte suplementar da pastagem.

Semeado em abril, o azevém anual produziu em torno de $30 \%$ a mais de matéria seca, e o seu período vegetativo foi 48 dias mais longo, em comparação com as semeaduras feitas em maio e junho. Isso propiciou dois cortes suplementares da pastagem.

Com relação à densidade de semeadura, podem-se utilizar na implantação 60 e $15 \mathrm{~kg} / \mathrm{ha}$ de sementes puras viáveis, respectivamente, para aveia preta e azevém anual.

Para obter uma distribuição mais adequada e complementar da produção forrageira no ano, o produtor pode utilizar as duas espécies de forma singular e/ou consorciada.

\section{Referências Bibliográficas}

ALMEIDA, E.X., VETTERLE, C.P., MIRANDA, M. et al. 2000. Forrageiras para região de clima subtropical úmido$C f a$. In: RECOMENDAÇÃ̃O DE CULTIVARES PARA O ESTADO DE SANTA CATARINA 2000/2001. Florianópolis, EPAGRI. p.75-90. (EPAGRI, Boletim Técnico, 107).

ALVIM, M.J., MARTINS, C.E. 1986. Efeito da densidade de semeadura sobre a produção de matéria seca da aveia e do azevém, em cultivos puros ou consorciados. R. Soc. Bras. Zootec., 15(4):285-296.

BARTZ, H.R., BISSANI, C.A., SCHERER, E.E., et al. 1995. Recomendações de adubação e de calagem para os Estados de Rio Grande do Sul e de Santa Catarina. Passo Fundo, RS: EMBRAPA - CNPT. 224p.

INSTITUTO DE PLANEJAMENTO E ECONOMIA AGRÍCOLA DE SANTA CATARINA. 1999. Sintese anual da agricultura de Santa Catarina. Florianópolis, SC. 170p.

JOSIFOVICH, J.A., MADDALONI, J., SERRANO, H. 1968. Producción de forrage verde y semilla de gramineas anuales de invierno según la época de siembra. Est. Exp. Pergamino. Inf. Téc. n: 72. Apud Carámbula, M. Producción y manejo de pasturas sembradas. Hemisfério Sur, Montevideo, s.d. 464p.

KALVElaGE, H.; PIANA, Z., DALL' AGNOL, M. 1989. Densidade de semeadura de azevém anual e aveia preta. $R$. Agropec. Catarinense, 2(1): 22-23.

MOZZER, O.L., CÓZER, A.C., SOUSA, R.M. et al. 1980. Efeito da época de plantio e da altura do corte na produção de aveia (Avena sativa L.) na Zona da Mata de Minas Gerais. R. Soc. Bras. Zootec., 9(4):537-548.

POSTIGLIONI, S.R. 1982. Comportamento da aveia, azevém e centeio na região dos Campos Gerais - PR. Londrina, IAPAR. 18 p. (Boletim Técnico - IAPAR, 14).

ROSA, J.L., RECH, T.D., FREITAS, E.A.G. 2000. Forrageiras para região de clima temperado úmido - Cfb. In: RECOMENDAÇÃO DE CULTIVARES PARA O ESTADO DE SANTA CATARINA 2000/2001. Florianópolis: EPAGRI. p.91-96. (EPAGRI, Boletim Técnico, 107).

SALERNO, A.R., VETTERLE, C.P. 1984. Avaliação de forrageiras de inverno no Baixo Vale do Itajaí, Santa Catarina. Florianópolis, EMPASC. 26p. (EMPASC, Comunicado Técnico, 76).

SAS Institute Inc. SAS/STAT ${ }^{\circledR}$ Users's Guide. Version 6, 4 ed., Cary, NC, 1990.

TCACENCO, F.A., HILLESHEIM, A. 1990. Pastagens anuais de inverno para as regiões subtropicais de Santa Catarina. R. Agropec. Catarinense, 3(3):13-16.

VIDOR, M.A., DALL'AGNOL, M., QUADROS, F.L.F. 1997. Principais forrageiras para o Planalto de Santa Catarina. Florianópolis, EPAGRI. 51p. (EPAGRI, Boletim Técnico, 86).

Recebido em: 08/11/00 Aceito em: 17/04/01 